Original paper

\title{
Teaching and learning of postgraduate medical physics using Internet-based e-learning during the COVID-19 pandemic - A case study from Malaysia
}

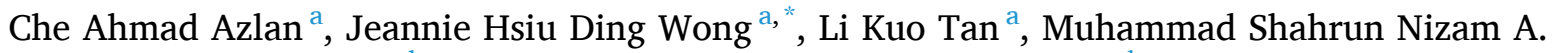 \\ D. Huri ${ }^{\mathrm{a}}$, Ngie Min Ung ${ }^{\mathrm{b}}$, Vinod Pallath ${ }^{\mathrm{c}}$, Christina Phoay Lay Tan ${ }^{\mathrm{d}}$, Chai Hong Yeong ${ }^{\mathrm{e}}$, \\ Kwan Hoong $\mathrm{Ng}^{\text {a,f }}$
}

${ }^{a}$ Department of Biomedical Imaging, Faculty of Medicine, University of Malaya, 50603 Kuala Lumpur, Malaysia

${ }^{\mathrm{b}}$ Clinical Oncology Unit, Faculty of Medicine, University of Malaya, 50603 Kuala Lumpur, Malaysia

${ }^{\mathrm{c}}$ Medical Education and Research Development Unit, Faculty of Medicine, University of Malaya, 50603 Kuala Lumpur, Malaysia

d Department of Primary Care Medicine, Faculty of Medicine, University of Malaya, 50603 Kuala Lumpur, Malaysia

${ }^{\mathrm{e}}$ School of Medicine, Faculty of Health and Medical Sciences, Taylor's University, 47500 Subang Jaya, Malaysia

${ }^{\mathrm{f}}$ Department of Medical Imaging and Radiological Sciences, College of Health Sciences, Kaohsiung Medical University, Kaohsiung, Taiwan

\section{A R T I C L E I N F O}

\section{Keywords:}

Medical physics education

E-learning

Virtual learning

COVID-19

\begin{abstract}
A B S T R A C T
Purpose: We present the implementation of e-learning in the Master of Medical Physics programme at the University of Malaya during a partial lockdown from March to June 2020 due to the COVID-19 pandemic. Methods: Teaching and Learning (T\&L) activities were conducted virtually on e-learning platforms. The students' experience and feedback were evaluated after 15 weeks.

Results: We found that while students preferred face-to-face, physical teaching, they were able to adapt to the new norm of e-learning. More than $60 \%$ of the students agreed that pre-recorded lectures and viewing videos of practical sessions, plus answering short questions, were beneficial. Certain aspects, such as hands-on practical and clinical experience, could never be replaced. The e-learning and study-from-home environment accorded a lot of flexibility. However, students also found it challenging to focus because of distractions, lack of engagement and mental stress. Technical problems, such as poor Internet connectivity and limited data plans, also compounded the problem.

Conclusion: We expect e-learning to prevail in future. Hybrid learning strategies, which includes face-to-face classes and e-learning, will become common, at least in the medical physics programme of the University of Malaya even after the pandemic.
\end{abstract}

\section{Introduction}

In November 2019, a novel coronavirus disease (COVID-19) that causes severe acute respiratory syndrome (SARS)-like symptoms was reported in Wuhan, China. The outbreak was soon declared a pandemic, infecting millions of people and causing nationwide lockdowns in more than 180 countries [1]. Malaysia was one of the countries affected by the pandemic; the first wave of infection started on January 24, 2020, and the second a month later. On March 18, 2020, the government imposed the Movement Control Order (MCO), which put the country on a partial lockdown $[2,3]$. Besides halting almost all socio-economic activities, non-essential services, including schools and universities, were instructed to close, and all teaching activities were migrated online. People were allowed to leave their homes for essential purposes only, such as to buy supplies or seek medical treatment.

The Master of Medical Physics (MMedPhys) programme at the University of Malaya in Kuala Lumpur, Malaysia, is no exception and contingency steps had to be taken to ensure lesson continuity. Established in 1998, the postgraduate degree has been accredited by the United Kingdom's Institute of Physics and Engineering (IPEM) since $2002[4,5]$. Medical physics, being a science and clinical discipline, is traditionally taught in a classroom didactic style [4]. The students attend face-to-face

\footnotetext{
* Corresponding author.

E-mail address: jeannie_wong80@um.edu.my (J.H.D. Wong).
} 
lectures and other teaching and learning (T\&L) activities within the campus. The course delivery includes lectures, tutorials, laboratory benchwork (hands-on sessions, demonstrations), clinical attachments and research projects. The training was also carried out in a clinical environment, requiring students to work with clinicians [4].

Due to COVID-19 and lockdown, we were compelled to deliver education through e-learning. We drew upon our earlier experience in teleteaching [6-9]. In this paper, we present a quick overview of the learning tools currently available and utilised in our approach to provide online T\&L of medical physics postgraduate education at the University of Malaya, in relation to learning theory and a model of learning.

\subsection{A medical education perspective}

Higher education in Malaysia in general and at the University of Malaya in this context has been following the time-tested approach of outcome-based education. The underlying intention in the whole process is to provide the students with clearly defined outcomes or achievement targets and create learning opportunities to ensure the achievement of learning outcomes. The entire process of learning would then be aligned to the achievement of the outcomes, and the learner achievement of outcomes is then assessed through a comprehensive system of assessments. This pedagogical structure would ensure the curriculum taught, instructional methods employed, learning environment created (both physical and virtual), and assessments are aligned to facilitate effective learning [10].

The theoretical basis of this 'constructive alignment' would be 'constructivism'. 'Constructivism' represents the cognitive viewpoint of the psychological theories of learning where learning is developed through the active involvement of the learner. Learners are assisted in constructing the meaning of what they learned through relevant learning activities. The alignment of activities of instruction, where the learning opportunities provided, instructional approaches used, and the learning environment created, would enable the learner to develop meaning or learn well.

Even with a perfectly aligned constructivist approach, students would behave and learn differently. To capture all the diversity, a learning framework that will link the theory to practice is required. The 3P model (Presage - Process - Product) model (Fig. 1) proposed by Biggs et al. [12] helps to align the students' diversity, the educational environment, both physical and virtual created, and the outcomes achieved [11].

If the learning is occurring in a virtual online mode, awareness and application of this model would be valuable in ensuring that the instructional approaches and learning contexts created should support the needs of the learner in the form of a conducive Virtual Learning Environment (VLE). This VLE should support the constructive alignment of the curriculum and assessment with the course learning outcomes.

\subsection{The virtual learning environment and e-learning tools}

Harnessing the suitable education technology is crucial in e-learning delivery. Fig. 2 shows how T\&L activities can broadly be divided into four quadrants in the whole canvas of technology-enhanced learning. The vertical axis shows technologies that enable asynchronous activities to become synchronous, while the horizontal axis ranged from technology-supported activities to technology-enabled ones. The left lower quadrant requires minimal technical support and student engagement. However, it may be appropriate in a situation where the general e-learning environment is less favourable, or the group is still treading in the early stages of e-learning. As we move towards the upper right quadrant, more mature technologies will enable better, real-time student engagement with a wider variety of instructional delivery support via a suitable VLE, such as Moodle or Blackboard. While the education-learner interaction may be enhanced, it requires good Internet connectivity, big data plans and higher technological cost.

E-learning T\&L requires a suitable VLE, also referred to as learning management systems (LMS). VLEs enable the management of online learning, provides a delivery mechanism, keeps track of the students' activities and assessment, and provides access to digital resources [13]. These platforms offer a wide range of educational features, including online classrooms, forums and material exchanges. VLEs allow students to access course materials, such as pre-recorded lectures, assignments and quizzes from the comfort of their home using computers, tablets and smartphones. A brief list of available and commonly used online VLEs is shown in Table 1.

The modes of delivery for e-learning can be divided into two categories: synchronous or asynchronous. Synchronous delivery is similar to a traditional classroom environment, except the interaction is virtual instead of physical. Examples of activities that may be conducted through this mode are lectures, tutorials, quizzes and discussions. The use of video-conferencing platforms is essential. Examples like Microsoft Teams and Skype (Microsoft Corp, Redmond, WA, United States), Google Meet (Google LLC, Mountain View, CA, United States), Zoom (Zoom Video Communications, San Jose, CA, United States), Cisco WebEx (Cisco WebEx LLC, Milpitas, CA, United States), BigBlueButton

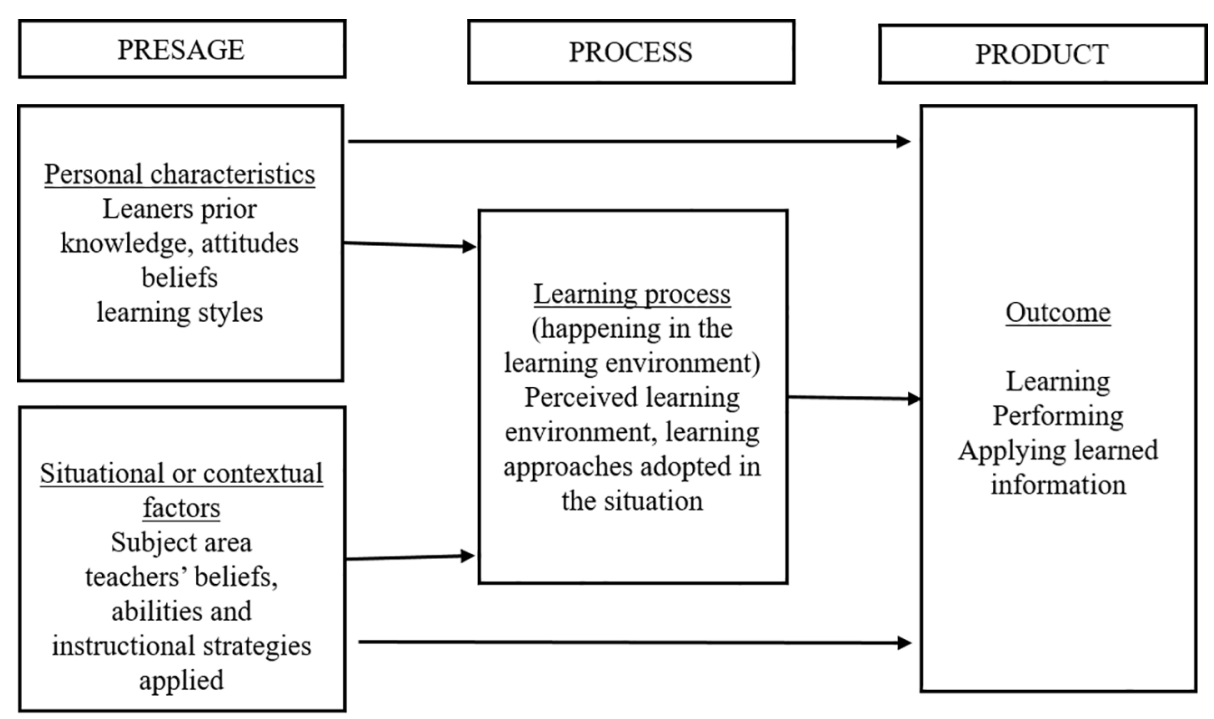

Fig. 1. Biggs 3P model that links students' diversity with the learning process and their outcome (adapted and modified from Dig Biggs et al. [12]. 


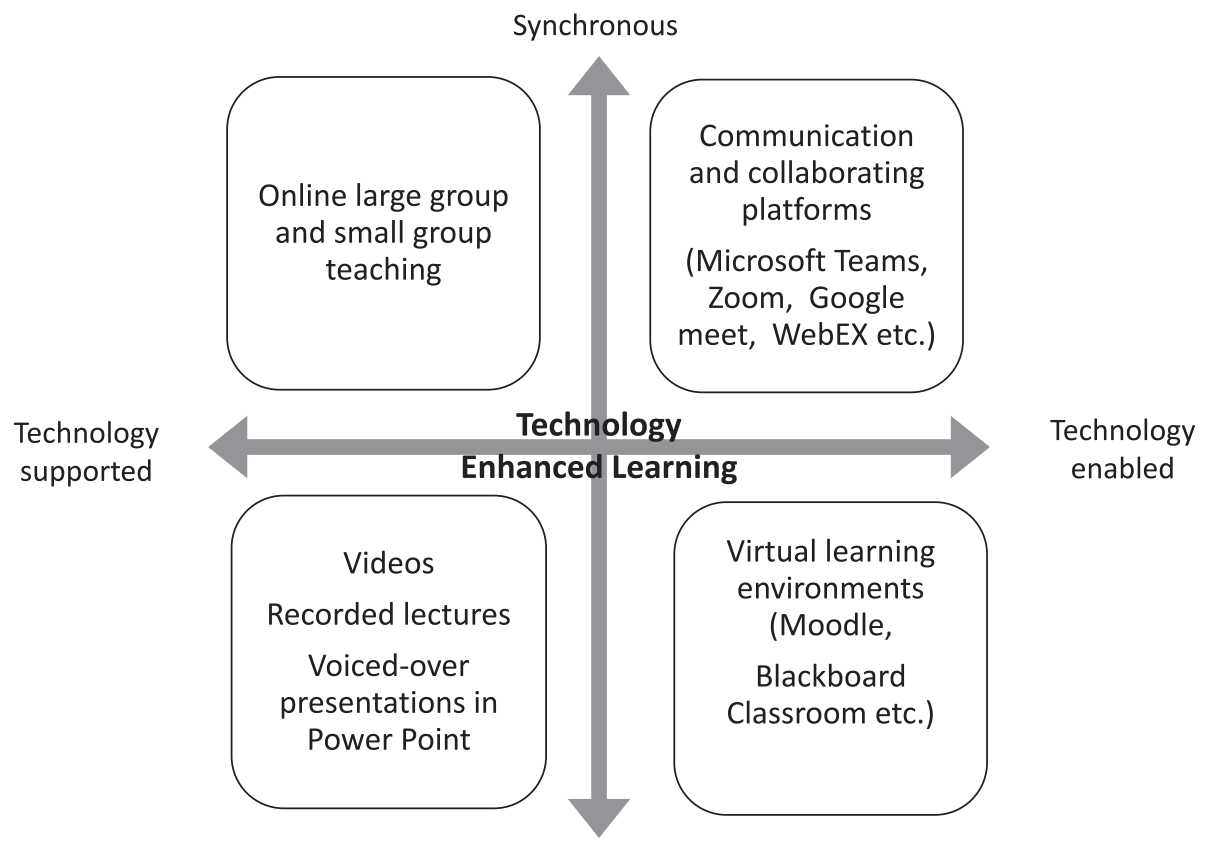

Asynchronous

Fig. 2. Four quadrants of activities in technology-enhanced learning.

Table 1

Some commonly used virtual learning environment (VLE) tools.

\begin{tabular}{|c|c|c|c|}
\hline $\begin{array}{l}\text { Software } \\
\text { (Developer) }\end{array}$ & Main features & Advantages & Limitations \\
\hline $\begin{array}{l}\text { Moodle } \\
\text { (Moodle Pty } \\
\text { Ltd) }\end{array}$ & $\begin{array}{l}\text { - A full-featured } \\
\text { open-source VLE } \\
\text { platform with a } \\
\text { modular design }\end{array}$ & $\begin{array}{l}\text { - Complete, very } \\
\text { customisable and } \\
\text { free usage of } \\
\text { essential functions }\end{array}$ & $\begin{array}{l}\text { - Not user- } \\
\text { friendly }\end{array}$ \\
\hline $\begin{array}{l}\text { Blackboard } \\
\text { (Blackboard } \\
\text { Inc) }\end{array}$ & $\begin{array}{l}\text { - Comprehensive } \\
\text { proprietary VLE } \\
\text { platform }\end{array}$ & $\begin{array}{l}\text { - Very user-friendly } \\
\text { for teachers and } \\
\text { students }\end{array}$ & $\begin{array}{l}\text {-Expensive } \\
\text {-Limited number } \\
\text { of users }\end{array}$ \\
\hline $\begin{array}{l}\text { Canvas } \\
\text { (Instructure } \\
\text { Inc) }\end{array}$ & $\begin{array}{l}\text { - Open source VLE } \\
\text { platform }\end{array}$ & $\begin{array}{l}\text { - User-friendly } \\
\text { platform }\end{array}$ & $\begin{array}{l}\text {-Lack of } \\
\text { customisation } \\
\text { capabilities }\end{array}$ \\
\hline $\begin{array}{l}\text { Google } \\
\text { Classroom } \\
\text { (Google } \\
\text { LLC) }\end{array}$ & $\begin{array}{l}\text { - VLE to enhance } \\
\text { students-educator } \\
\text { collaboration }\end{array}$ & $\begin{array}{l}\text { - Simple interface, } \\
\text { user-friendly and } \\
\text { full integration } \\
\text { with Google G } \\
\text { Suite }\end{array}$ & $\begin{array}{l}\text {-Limited } \\
\text { functions } \\
\text { compared to } \\
\text { other platforms }\end{array}$ \\
\hline
\end{tabular}

(BigBlueButton Inc.) and Jitsi (Jitsi.org) are listed in Table 2. Most of these apps offer limited functionality as a free package, and more functions may be accessed only through paid packages. Unless the university or college subscribes to the apps, most academics and students are unwilling to pay the cost and prefer to work within the limitations of the free package.

Other than video calls and text chat functionality, most software allows lecturers to share slides and display computer screens in realtime, enabling an interactive explanation of lessons. Most videoconferencing apps also allow recording of online sessions, which can be uploaded to the Internet and reviewed by students.

To foster active engagement and constructivism among students, lecturers can integrate polling tools into their online teaching. Examples include Mentimeter (Mentimeter Company, Stockholm, Sweden), Poll Everywhere (Poll Everywhere, San Francisco, CA, United States), Slido (sli.do s.r.o., Bratislava, Slovakia), Kahoot! (Kahoot!, Oslo, Norway), Quizizz (Quizizz Inc., CA, United States) and iClicker (Macmillan Learning, NY, United States). Such tools can also engage students in learning activities. Some of the video platforms include such polling tools already, e.g., Cisco WebEx, MS Teams, BigBlueButton and Jitsi. Polling tools embedded in the video platforms are much easier and quicker to use during teaching for the lecturer and the audience. The need to switch to a different website needs considerable time and is an additional source of technical problems. Another benefit of polling tools is that they can be used to automatically record students' participation by asking them to input their student number or name before answering questions. The use of these polling tools and online quizzes are also

Table 2

Comparison of selected video-conferencing apps for T\&L applications*.

\begin{tabular}{|c|c|c|c|c|c|c|c|}
\hline Description & Google Meet & Cisco WebEx & MS Teams & Zoom & Skype & BigBlueButton & Jitsi \\
\hline Free version & Yes & Yes & Yes & Yes & Yes & Yes & Yes \\
\hline Time limit & 60 mins & $24 \mathrm{~h}$ & No limit & 40 mins & $10 \mathrm{~h}$ & No limit & No limit \\
\hline Max. No. of participants & 100 & 200 & 250 & 100 & 50 & 150 & 75 \\
\hline User-friendly & Yes & No & No & Yes & Yes & Yes & Yes \\
\hline Screen sharing & Yes & Yes & Yes & Yes & Yes & Yes & Yes \\
\hline Whiteboard & No & Yes & Yes & Yes & No & Yes & No \\
\hline Meeting recording & Yes & Yes & Yes & Yes & Yes & Yes & Yes \\
\hline Polling tools included & No & Yes & Yes & No & No & Yes & Yes \\
\hline End-to-end encryption & No & Yes (optional) & No & No & Yes (optional) & No & No \\
\hline Plans (US\$ per month) & 6.00 & 13.50 & 5.00 & 14.99 & 2.99 & - & - \\
\hline Mobile app & Yes & Yes & Yes & Yes & Yes & No & Yes \\
\hline
\end{tabular}

Note: These features are for basic, non-paying packages. 
useful as a form of formative assessment.

The main disadvantage of the synchronous mode is that the effectiveness of teaching delivery depends heavily on the quality of the Internet connection. A bad connection may result in disruptions during live sessions, and this affects the quality of course delivery. This problem is more pronounced for students in rural areas with limited Internet infrastructure, or those who cannot afford expensive monthly data plans and have to rely on pay-as-you-go Internet connectivity plans.

For the asynchronous mode of delivery, the educator-learners interaction is not instantaneous, i.e., T\&L activities not only occur at different locations but also at different times. Examples are prerecorded video lectures, lecture slides, external resources such as YouTube videos or educational websites, offline tests and assignments. The students' feedback can be sent through email or messaging apps like WhatsApp (WhatsApp Inc, Santa Clara, CA, United States), Telegram (Telegram Messenger LLP, London, United Kingdom) and Facebook Messenger (Facebook, Inc, Menlo Park, CA, United States). The main advantage of this offline mode is that it provides flexibility to lecturers and students to teach and learn, respectively, at their own suitable time and this is less dependent on the quality of either party's Internet connection. Another advantage is that it gives opportunities for students to understand lessons at their own pace by viewing the content as often as they wish.

For group work, students can collaborate and hold virtual discussions via Microsoft Teams, Google Meet and WhatsApp. For assignments and tests, the educator can set time limits and due dates for submission. Proof of student participation can be obtained from electronic time stamps of the students' online activity.

The obvious drawback of asynchronous teaching is that there is no active interaction between lecturers and students. The students do not get immediate clarification when they run into problems or have difficulty understanding concepts. This method also requires self-discipline if no specific timeframes are set for viewing of materials. Furthermore, due to the minimum interaction, the students may be less motivated to study on their own.

\section{Materials \& methods}

At the University of Malaya, before COVID-19, we had already utilised a VLE called Student Powered e-Collaboration Transforming the University of Malaya (SPeCTRUM). This platform is based on Moodle, and it was mainly used as part of blended learning strategies implemented by the university. The system was intended to deliver lectures, assignments and examinations in a systematic and integrated manner. However, due to its user interface complexity and highly customisable environment, it was not fully utilised university-wide, with the level of implementation and adoption varying massively among individual courses and lecturers.

In the MMedPhys programme, SPeCTRUM was used to upload course information, lecture notes, instructions for assignments, and to post quizzes. Besides, Google Drive cloud storage was also used to distribute materials to students. These two apps had been proven to be excellent platforms for sharing files, but they are not complete solutions to virtual course delivery.

All teaching-learning activities were designed to ensure the constructive alignment of the curriculum. The learning objectives were aligned with T\&L activities and assessments. Approximate learning time was also calculated during the development of instructional strategies. In converting to online instructional delivery mode, students were required to invest a comparable amount of time to ensure appropriate learning.

For instructional delivery, a combination of synchronous and asynchronous methods was implemented. Table 3 shows the summary of the changes in the T\&L activities before the pandemic and during MCO. For lectures, the method of choice was pre-recorded videos uploaded into SPeCTRUM and Google Drive. Given that students had variable levels of
Table 3

Summary of the T\&L activities in University of Malaya's MMedPhys programme before and during the Covid-19 pandemic, including under MCO.

\begin{tabular}{|c|c|c|}
\hline Activities & Before Covid-19 & $\begin{array}{l}\text { During Covid-19 pandemic \& } \\
\text { under MCO }\end{array}$ \\
\hline \multirow[t]{3}{*}{$\begin{array}{l}\text { Teaching \& } \\
\text { Learning }\end{array}$} & Face-to-face lectures. & $\begin{array}{l}\text { Pre-recorded videos }+ \text { online } \\
\text { discussion. }\end{array}$ \\
\hline & $\begin{array}{l}\text { Hands-on practicals, } \\
\text { demonstration and } \\
\text { submission of practical } \\
\text { reports. }\end{array}$ & $\begin{array}{l}\text { Viewing of videos recordings } \\
\text { of practicals and those } \\
\text { available from websites. } \\
\text { Students were required to } \\
\text { answer questions after } \\
\text { viewing the videos. }\end{array}$ \\
\hline & $\begin{array}{l}\text { Logbook record of clinical } \\
\text { postings and observations. }\end{array}$ & Discontinued. \\
\hline \multirow[t]{3}{*}{ Assessments } & Written assignments. & $\begin{array}{l}\text { Assignments submitted } \\
\text { online. }\end{array}$ \\
\hline & Oral presentations. & Video presentations. \\
\hline & Written examination. & $\begin{array}{l}\text { Multiple-choice-questions } \\
\text { (MCQs) and tests } \\
\text { administered via online } \\
\text { platforms, such as Google } \\
\text { Form or SPeCTRUM. }\end{array}$ \\
\hline Research Project & $\begin{array}{l}\text { Experimental and clinical } \\
\text { research work that required } \\
\text { data collection in the hospital. }\end{array}$ & $\begin{array}{l}\text { Experimental and clinical } \\
\text { research work that required } \\
\text { data collection in the hospital. } \\
\text { Special permission was } \\
\text { obtained for students to } \\
\text { access hospital facilities and } \\
\text { collect data. } \\
\text { The amount of data needed } \\
\text { was reduced. }\end{array}$ \\
\hline Final Exam & Closed book. & $\begin{array}{l}\text { Open book. } \\
\text { Most questions required } \\
\text { students to apply higher- } \\
\text { order thinking skills (HOTS). }\end{array}$ \\
\hline $\begin{array}{l}\text { Oral } \\
\text { Examination }\end{array}$ & $\begin{array}{l}\text { The physical presence of } \\
\text { external examiner during the } \\
\text { oral examination was } \\
\text { required. }\end{array}$ & $\begin{array}{l}\text { Student makes a short video } \\
\text { recording of their } \\
\text { presentation and question } \\
\text { and answers session } \\
\text { conducted online via MS } \\
\text { Team. }\end{array}$ \\
\hline $\begin{array}{l}\text { Student } \\
\text { engagement }\end{array}$ & $\begin{array}{l}\text { Face-to-face interactions and } \\
\text { discussions. }\end{array}$ & $\begin{array}{l}\text { Online meeting, Kahoot! and } \\
\text { Google form MCQs. }\end{array}$ \\
\hline Communication & Verbal, WhatsApp and email. & WhatsApp and email. \\
\hline $\begin{array}{l}\text { VLE/cloud } \\
\text { storage }\end{array}$ & SPeCTRUM and Google Drive. & SPeCTRUM and Google Drive. \\
\hline $\begin{array}{l}\text { Attendance } \\
\text { record }\end{array}$ & $\begin{array}{l}\text { Signature on the attendance } \\
\text { sheet. }\end{array}$ & Google form. \\
\hline
\end{tabular}

Internet connectivity, and that a typical lecture usually lasted an hour, asynchronous video recordings were chosen to minimise disruptions and potential connectivity issues.

The videos were compressed and resized to an adequate resolution (usually 720p) for easy viewing and download in all devices. A typical one-hour lecture might end up with a video recording of 100 to 300 megabytes, depending on complexity. Several synchronous sessions were also done to supplement pre-recorded lectures. These sessions were mainly used to give opportunities to students to ask questions related to the pre-recorded lectures. The students were asked to view the uploaded lectures and read the lecture notes before the live session. For research projects, students were barred from coming to classes and working in the hospital during the pandemic and, as such, those whose project required access to clinical machines, instead, spent their time doing literature reviews, analysing data and writing their project report. All communications between students and supervisors were done via messaging software, email and video conferencing.

To replace laboratory-based hands-on practical sessions, either practical sessions (e.g. machine quality control procedures) were prerecorded or external resources, such as YouTube videos containing medical physics experiments or procedures, were used. For the former, the students were asked to produce a lab report based on the virtual practical session. For the latter, students were given a series of questions 
to answer to demonstrate their understanding of the topic.

Despite the MCO and virtual learning conditions, students' attendance was still required by the university. A simple method to record attendance was utilised by capturing a screenshot of the list of participants during synchronous sessions. However, this method was only feasible for small groups. The lecturers eventually settled on utilising an online form - students were provided with a link and asked to record their attendance.

Part of the T\&L activities also included assessments. Some MMedPhys courses comprised $60 \%$ continuous and $40 \%$ final assessment. Conventionally, the final assessment involved a written examination. However, strict physical distancing measures meant that large gathering of students, including for examinations, were prohibited. Instead, the university gave flexibility for implementing alternative assessment methods. In the MMedPhys programme, the final examination component was retained. However, the assessment was done online via SPeCTRUM instead of conventional face-to-face evaluation. Most online VLE allowed lecturers to set online test submission time limits as in faceto-face examinations. We realised early on that it was not feasible to prevent students from "cheating", like searching the Internet for answers. Although monitoring of students during examination sessions using web cameras was possible, it carried too many intractable issues. For example, students may be experiencing genuine technical problems with their webcam, or they could be cheating by placing reference materials behind the webcam. Additionally, such close monitoring was only feasible with smaller staff-to-student ratios.

The alternative was, therefore, to make all examinations an opened book format. However, this required questions to test the students' higher-order thinking skills (HOTS); thus, questions testing knowledge recall were kept to a minimum. The examination question format was retained, but instead of a printed copy, the questions were presented in PDF format. The question papers were uploaded to SPeCTRUM with a specific date and time for students to download. The students were asked to answer the questions by writing on standard A4 paper. They were required to submit the answer within three to three and a half hours. They scanned their answer scripts using a smartphone PDF maker app, such as Microsoft Office Lens (Microsoft Corp, Redmond, WA, United States) and CamScanner (IntSig Information Co., Ltd, Shanghai, China). The PDF answer scripts were uploaded to designated folders in the SPeCTRUM system. For marking, the lecturers either marked directly on the PDF answer scripts or printed out a paper copy to do so.

Almost 10 weeks after the MCO was imposed, the government began relaxing restrictions and allowed postgraduate students to return to campus to work under strict standard operating procedures (SOPs). The MMedPhys programme was classified as a coursework mode. Hence a special arrangement was made with the university management to allow students to continue their data collection. To ensure that the programme continued to maintain the standards and requirements of IPEM, the general structure of the project and report format were retained.

An evaluation was carried out at the end of the semester on July 27, 2020, which was 15 weeks after the MCO was implemented. The students' feedback on the change to e-learning was recorded in a questionnaire (Table 4). In the survey, comparative questions between faceto-face lectures and all e-learning methods were asked as the students had undergone six weeks of face-to-face lectures before converting to online lessons. In this way, the two delivery modes of the same course could be compared in the same batch of students.

\section{Results}

The current batch in the MMedPhys programme during the pandemic comprised a total of 11 students. Fig. 3 shows the results of their evaluation. The response rate was $100 \%$, and it showed that the students still preferred face-to-face lectures compared to e-learning modes. They found the physical lecture sessions less boring, more engaging and enabling them to ask questions directly to lecturers.
Table 4

Evaluation questions for MMedPhys programme students at University of Malaya.

1. To what extent do you find the following activities useful in your learning? Range from: 1 (Not useful at all) to 5 (Very useful).

A Face-to-face lectures

B Pre-recorded videos

C Online discussion sessions

D Viewing of videos recordings of practicals and those available from websites + answering of short answer questions

E MCQs

F Kahoot!

G Video presentation

2. The pre-recorded videos/lectures

A were very clear and helped me to prepare for my lessons.

B were not clear, and I did not understand the lesson.

C I didn't have time to review it.

D Other

3. The online discussion sessions were

A very useful and help me to understand the lessons better.

B a waste of my time.

C able to help me engage with the lecturers.

D able to help me engage with my coursemates.

E Other

4. Viewing of videos recordings of practicals and those available from websites + answering of short answer questions

A help me to understand the topic better.

B did not help me to understand the topic better.

C Other

5. The activities involving MCQs and Kahoot!

A helped me to understand the topic better.

B did not help me to understand the topic better.

C were fun.

D were stressful.

E were useless.

F Other

6. What challenges did you face because of the shift from the physical classroom to a complete e-learning environment? [Free text replies]

7. What do you think is the positive sides of the online e-learning experience? [Free text replies]

8. Would you say you have adequate support as a student? What kind of support do you wish you had? [Free text replies]

9. What would you say has helped you with this transition? [Free text replies]

The pre-recorded videos/lectures were well-received by students, with $64 \%(7 / 11)$ saying that they were very clear and helped them prepare for their lessons. However, they found that some recordings were lengthy and not very engaging. Some students also did not have time to focus on the videos, which was a particular problem for those with family commitments and young children.

Less than half of the students felt that the online discussions had helped them to understand their lessons better (5/11) and to engage with the lecturers $(3 / 11)$. Students were better engaged when lecturers actively asked them questions to encourage their understanding of a specific topic.

A total of 73\% (8/11) of students said viewing video recordings of practical training and answering short questions had helped them to understand a topic better. However, the videos only provided them with a general idea of practice and not experience in the real clinical setting.

Online quizzes, given as multiple-choice questions (MCQs) and Kahoot! were carried out as formative assessments besides prompting questions from students. Although seven out of the 11 students said these activities were fun and had helped them to understand their topics better, two students said they felt stressful completing the tasks. The student-engagement activities were severely limited by intermittent Internet connectivity as it hampered participation and was sort of an anti-climax.

Concerning challenges faced because of the shift from the physical classroom to a complete e-learning environment, students reported a drop in morale, loss of motivation, difficulty focussing on their studies and Internet connectivity problems. The new learning norm required them to be more independent and self-regulating in their learning 


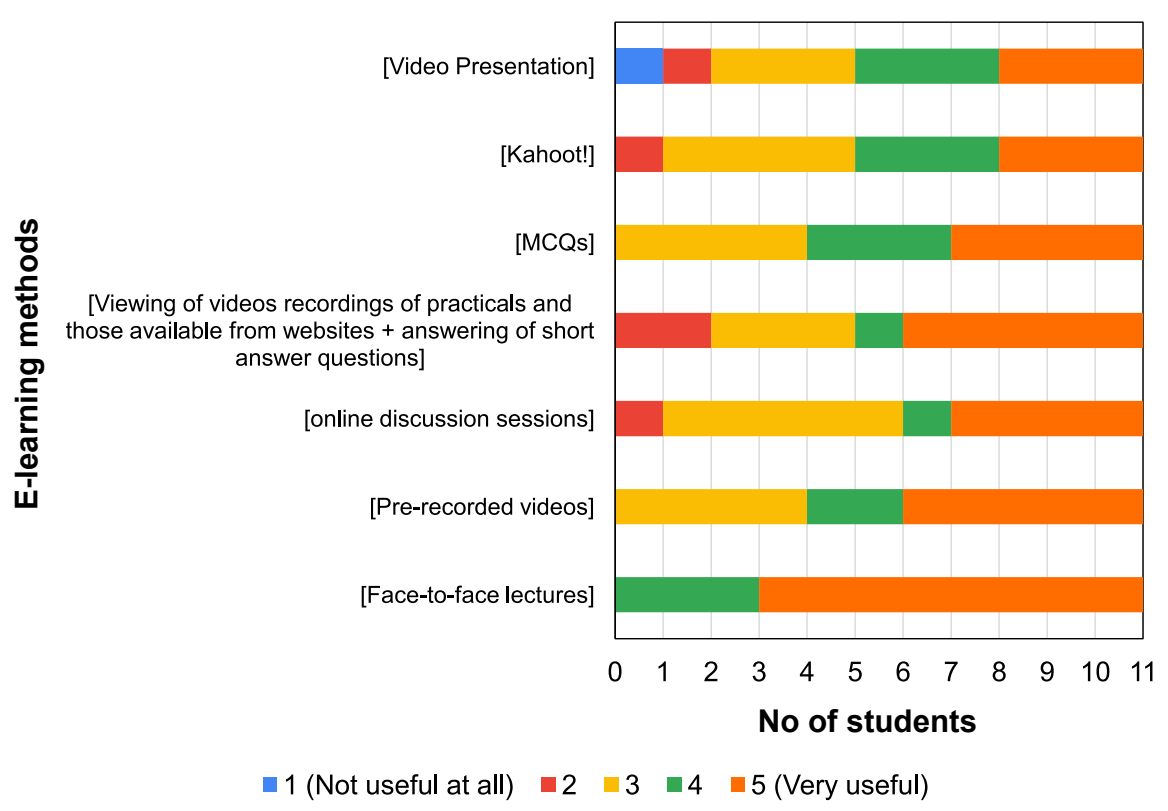

Fig. 3. Results of perceived student satisfaction with online learning in the MMedPhys programme.

approaches. They were also concerned with the lack of real clinical experience. On the other hand, the pre-recorded lectures accorded flexibility in learning, and students could review the recordings multiple times to refresh their memories. For some students who used to spend long hours travelling from home to work, the study-from-home mode was a definite advantage to reduce unnecessary time spent on travelling.

One-half of the students reported that they had adequate support from the staff, family and friends during this challenging period. Students reported lack of support in terms of resources such as access to library books, and the clinical attachment as part of their training. Another vital aspect that did not receive adequate attention was the mental support for the students, as this may be a sensitive and private issue; some students found that it is difficult to seek professional help.

\section{Discussion}

COVID-19 had posed an unprecedented challenge in T\&L activities at the University of Malaya, particularly in the MMedPhys programme. While a vaccine would take some time to be developed, medical physics training needed to continue during this pandemic and beyond. This called for new strategies and innovative methods to be developed and adopted. The most logical way for educators was to adopt Internet-based technologies in the delivery of education.

On the positive side, Internet-based e-learning could be more convenient and cost-effective compared to traditional classroom learning. This learning approach could be an excellent method to deliver conventional lectures and tutorials. However, due to the clinical and practical nature of postgraduate medical physics training, not all T\&L components were suitable to be delivered online. Laboratory or workplace-based learning sessions, clinical attachments, and clinical research projects were among learning activities which were more appropriate to be conducted physically on campus.

Another major obstacle is that not all students could afford to subscribe to fixed-line Internet, which provides a stable connection with unlimited data. The accessibility and quality of Internet connectivity, wireless communication, and computer and smartphone technology had improved significantly in the past decade. In Malaysia, a developing middle-income country, these technologies could now be accessed by most of the population.

However, despite this growth, the speed and reliability of Internet connectivity were not homogenous, making online lessons unconducive. In general, the quality of Internet connectivity in rural areas was much lower compared to urban areas. Considering $22 \%$ of Malaysians live in rural areas, this remained a significant problem [14]. The situation was compounded by poverty, where some students, including schoolchildren from low-income families, had to rely solely on prepaid mobile Internet data plans and even share their digital devices. One family might own one or two mobile phones only, which were used by many members. Usually, such cheaper plans had low quotas of 1 to 10 gigabytes (GB) per month. A 1 GB limit could be quickly exhausted when downloading several videos or attending a few synchronous sessions. These issues were the main challenges in the implementation of total online elearning for university students in Malaysia. To address this limitation, we could explore other video streaming platforms that offered different streaming formats and resolutions, such that a student could choose a lower resolution for viewing to save their data allocations.

We found that in the lectures, students preferred short pre-recorded talks. We learnt that while the recorded lectures were the most straightforward method in carrying out online teaching, student engagement was lacking far behind. Modern e-learning didactics also recommended a combination of short condensed input (e.g. videos) interlaced with online activities, engaging students in active participation or formative assessments (such as MCQs, calculation tasks, thoughtprovoking questions). These techniques enabled an interactive connection with students, leveraging their short-term attention while reinforcing students' understanding of the topic. However, it should be noted that the optimum duration of any lecture, either face-to-face or online, would vary and depended much on the lecturers' teaching skills [15]. Hence, to improve the effectiveness of pre-recorded lectures, it was suggested that a lengthy topic be divided into several short videos instead of a single long video.

From our experience, it was also recommended to conduct online sessions after students had viewed their pre-recorded lectures. These sessions could be used to answer questions from students and explain more about some difficult concepts. In addition to lectures, other T\&L methods, such as computer simulation, quizzes and video animation, could also be used to supplement the lectures.

Another critical issue that needs to be addressed by educators was the mental health impact on students. Due to this pandemic, students' social life had been affected drastically. For example, they could not 
socialise with their friends and were restricted to sharing a confined living space with their family or colleagues, which was not a conducive study environment. Besides, some students might also be grieving over the loss of loved ones to the pandemic or some other unfortunate circumstances, among the common physiological effects that have been reported included loneliness, anxiety, stress and depression [16,17]. Therefore, it is crucial for educators and university administrators to monitor this situation and show empathy towards the students. Nevertheless, despite these issues, the learning had to continue. Lecturers and university administrators must be creative and innovative to ensure that the use of online education is maximised among their students.

\section{Conclusion}

Due to the COVID-19 pandemic and MCO, the instructional delivery of MMedPhys in the University of Malaya had to be shifted from the traditional campus-based education to Internet-based e-learning. We predict that even after the COVID-19 crisis, the new norm of T\&L will continue, perhaps into another form of symbiotic co-existence of hybrid learning, where e-learning activities would complement effectively with face-to-face activities. Indeed, the experience gained during the pandemic has enriched and broadened the approach to T\&L in the MMedPhys course at the University of Malaya. However, it must be recognised that an effective, efficient and engaging online instructional delivery did not merely involve recorded lectures and online meetings! There was a need to explore other online collaborative learning tools to improve instructional delivery and increase student engagement. It should be remembered that "Learning is the goal and technology is just the environment".

\section{Declaration of Competing Interest}

The authors declare that they have no known competing financial interests or personal relationships that could have appeared to influence the work reported in this paper.

\section{Appendix A. Supplementary data}

Supplementary data to this article can be found online at https://doi. org/10.1016/j.ejmp.2020.10.002.

\section{References}

[1] Johns Hopkins University. Johns Hopkins Coronavirus Resource Center 2020.

[2] Ministry of Health Malaysia. COVID-19 current situation in Malaysia.

[3] World Health Organization (WHO). COVID-19 situation overview in Malaysia 2020.

[4] Wong JHD, Ng KH, Sarasanandarajah S. Survey of postgraduate medical physics programmes in the Asia-Oceania region. Physica Med 2019;66:21-8.

[5] Wong JHD, Zin HM, Pawanchek M, Ng KH. Medical physicists in Malaysia: A national workforce survey 2019. Physica Med 2019;67:40-9.

[6] Woo M, Ng KH. Real-time teleteaching in medical physics. Biomed Imaging Intervention J 2008;4:e13.

[7] Woo MK, Ng KH. A model for online interactive remote education for medical physics using the Internet. J Med Internet Res. 2003 5:e3-e.

[8] Sprawls P. The Sprawls Resources. Sprawls Educational Foundation.

[9] Sprawls P, Tabakov S. A model for effective and efficient teleteaching of medical physics. In: Dössel O, Schlegel WC, editors. World Congress on Medical Physics and Biomedical Engineering, September 7-12, 2009, Munich, Germany. Springer, Berlin Heidelberg: Berlin, Heidelberg; 2009. p. 221-2.

[10] Biggs J. Aligning teaching for constructing learning. The Higher Education Academy 2002.

[11] Tan BS, Wong SL. Learning principles of accounting in ICT-supported learning environments of Malaysian secondary schools: future-oriented approach. Research and Practice in Technology Enhanced Learning. 2020;15:11.

[12] Biggs J, Kember D, Leung DYP. The revised two-factor Study Process Questionnaire: R-SPQ-2F. Br J Educ Psychol 2001;71:133-49.

[13] McAvinia C. Online learning and its users. Chandos Publishing 2016.

[14] Demographics Malaysia. Malaysia Demographics 2020 (Population, Age, SThe current batch in the MMedPhys ex, Trends) - Worldometers. 2019. Available at (https://www.worldometers.info/demographics/malaysia-demographics/).

[15] Bradbury NA. Attention span during lectures: 8 seconds, 10 minutes, or more? Adv Physiol Educ 2016;40:509-13.

[16] Odriozola-González P, Planchuelo-Gómez Á, Irurtia MJ, de Luis-García R. Psychological effects of the COVID-19 outbreak and lockdown among students and workers of a Spanish university. Psychiatry Res 2020;290:113108.

[17] Cao W, Fang Z, Hou G, Han M, Xu X, Dong J, et al. The psychological impact of the COVID-19 epidemic on college students in China. Psychiatry Res 2020;287: 112934. 